\title{
Stages of Change for Increasing Fruit and Vegetable Intake in a Japanese Population
}

\author{
Da-Hong Wang ${ }^{1}$, Michiko Kogashiwa ${ }^{2 *}$, Naoko Mori ${ }^{3 *}$, Shikibu Yamashita ${ }^{4}$, Wakako Fujii ${ }^{5}$, Nobuo Ueda ${ }^{6}$, \\ Hiroto Homma ${ }^{7}$, Hisao Suzuki ${ }^{8} \&$ Noriyoshi Masuoka ${ }^{9}$ \\ ${ }^{1}$ Department of Biochemistry, Okayama University of Science, Okayama, Japan \\ ${ }^{2}$ Former affiliation: Department of Health and Nutrition, Junior College of Shimane University, Matsue, Japan \\ ${ }^{3}$ Department of Human Nutrition, Faculty of Human Nutrition, Seitoku University, Matudo, Japan \\ ${ }^{4}$ 16-12 Okuchi Kamimachi, Isa-shi, Kagoshima, Japan \\ ${ }^{5}$ Department of Nutrition, Mimasaka Junior College, Tsuyama, Japan \\ ${ }^{6}$ Department of Health and Nutrition, Faculty of Human Health, Kanazawa Gakuin University, Kanazawa, Japan \\ ${ }^{7}$ Department of Brewing and Fermentation, Junior College of Tokyo University of Agriculture, Tokyo, Japan \\ ${ }^{8}$ Institute for Education and Student Services, Okayama University, Okayama, Japan \\ ${ }^{9}$ CDW Labarotoy of Life science, ORIC, Okayama, Japan \\ Correspondence: Da-Hong Wang, Department of Biochemistry, Okayama University of Science, 1-1 Ridai-cho, \\ Okayama 700-0005, Japan. Tel: 81-86-256-9551. E-mail: dahong@dbc.ous.ac.jp
}

*These authors contributed equally to this work.

Received: May 10, 2019 Accepted: June 3, 2019 Online Published: June 19, 2019

doi:10.5539/gjhs.v11n7p139 URL: https://doi.org/10.5539/gjhs.v11n7p139

\begin{abstract}
Objective: Thhis study aimed to investigate the reason why people choose to consume less vegetable and fruit through examining how the stage of change and psycho-social parameters relate to vegetable and fruit intake.
\end{abstract}

Methods: We carried out a cross-sectional study in 4 regions of Japan in which 2308 individuals (1012 men and 1296 women) aged 18 years or older who completed the questionnaires were included in the study.

Results: The results showed $56 \%$ of the participants were in the precontemplation stage (not thinking about consuming recommended amount of fruit and vegetable) and their average amounts of vegetable and fruit intake were far below the level of current recommendations, and subjects in the precontemplation stage showed lower scores of attitude and self efficacy. Men were more likely to be in precontemplation (67.7\%) and less likely to be in action/maintenance stage $(7.9 \%)$ than women $(46.9 \%, 12.1 \%$, respectively) $(p<0.001)$. We also observed the scores of attitude $(p=0.06)$ and self-efficacy $(p<0.01)$ rose as the stage went up from the precontemplation to action/maintenance for increasing vegetable and fruit intake. Moreover, a linear trend was found toward higher vegetable $(p<0.05)$ and fruit $(p=0.121)$ intake from precontemplation to action/maintenance stage.

Conclusion: The present evidence suggests more attention should be focused on strategy for perceptions of personal need for recommended amount of vegetable and fruit intake for those who are in the precontemplation stage. Moreover, effective programs on enhancement of self-efficacy and attitude toward vegetable and fruit consumption are needed for increasing the vegetable and fruit intake.

Keywords: vegetable and fruit intake, stages of behavior change, knowledge, attitude, self-efficacy

\section{Introduction}

Adequate fruit and vegetable $(\mathrm{F} \& \mathrm{~V})$ intake have been reported to decrease the risk for many chronic diseases (Boeing et al., 2012) including ischemic stroke (Joshipura et al., 1999), cardiovascular disease (Bazzano, Serdula, \& Liu, 2003; Hartley et al., 2013), hip fracture (Byberg, Bellavia, Orsini, Wolk, \& Michaëlsson, 2015), and cancer (Block, Patterson, \& Subar, 1992; Van’t Veer, Jansen, Klerk, \& Kok, 2000; Wakai et al., 2015). In Japan, the daily recommended amounts of fruit and vegetable are $200 \mathrm{~g}$ or more and $350 \mathrm{~g}$ or more, respectively (Ministry of 
Health, 2000; Ministry of Agriculture, 2005); however, the average daily F\&V intakes remained low, $110.3 \mathrm{~g}$ and $277.4 \mathrm{~g}$ in 2011 and 107.6 g and 293.6 g in 2015, respectively (National Institute of Health and Nutrition, 2011; National Institute of Health and Nutrition, 2015). Therefore, understanding the real reasons why people do not consume more $\mathrm{F} \& \mathrm{~V}$ is crucial to the development of effective nutritional intervention programs.

Many studies have shown the psychological factors and the stages of readiness to change are related to $\mathrm{F} \& \mathrm{~V}$ intakes (Havas et al., 1998; Watters, Satia, \& Galanko, 2007; Shaikh, Yaroch, Nebeling, Yeh, \& Resnicow, 2008). A few studies in Japan have demonstrated that positive attitudes, self-efficacy, social support, and perceived barrier were associated with daily F\&V intakes (Kobayashi, Asakura, Suga, \& Sasaki, 2015; Okamoto, Nakao, \& Muto, 2015; Kato, 2011; Kato, Watanabe, Haga, Imada, \& Osada, 2014; Wang et al., 2016). However, there is limited evidence from Japan that addresses the association of the stage of behavioral change with daily F\&V intake as well as with psycho-social factors among general population. The present study aimed to understand why people choose to consume less $\mathrm{F} \& \mathrm{~V}$ through examining the stage of behavior change and psycho-social parameters of the subjects.

\section{Method}

\subsection{Study Design and Setting}

This study was a cross-sectional survey performed from October 2011 to June 2013. We collected the subjects conventionally from classes for college/university students, places of employment, and personal network in 4 regions of Japan (Chugoku region, Kinki region, Kyushu region, and Kanto region) (Wang et al., 2016).

\subsection{Participant Characteristics}

Three thousand one hundred and seventy-nine individuals aged 18 years or older were recruited, in which 1012 men (43.8\%) and 1296 women (56.2\%) who completed the questionnaires were included in the study.

Information on demographic characteristics, daily F\&V intake (instruction and examples were presented in the questionnaire), how the subject thinking about eating or planning to eat the recommended amount of $F \& V$, psycho-social parameters related to F\&V intake were collected through a self-administered questionnaire (Wang et al., 2016). The study design was approved by the Ethics Committee of Okayama University Graduate School of Medicine, Dentistry, and Pharmaceutical Sciences (EKI 529). Written informed consent was obtained from all participants in accordance with the principles stated in the Declaration of Helsinki.

\subsection{Measures}

\subsubsection{Vegetable and Fruit Intakes}

Vegetable and fruit intakes were assessed with food frequency questionnaire by asking whether they consumed the 38 items of fruits, vegetable, and juice (including fresh, cooked, frozen, canned and dried F\&V) on the day prior to the day of investigation, if the answer is "Yes", then asking "How many times yesterday" and "the serving size (small, medium, large)". The standard serving size with gram and volume was indicated in the questionnaire. General instructions about definition for fruit, vegetable, juice, and standard serving size (medium size) and examples were provided in the questionnaire. A sample of the questionnaire was kindly provided by Dr. Havas (Havas et al., 1998) and modified and tested for use in the Japanese population (Wang et al., 2016).

\subsubsection{Psycho-Socail Parameters}

Individual's psycho-social parameters (including nutritional knowledge, attitudes, responsibility, social support, self-efficacy, and perceived barriers) related to F\&V intake were measured by a questionnaire originally developed by Havas et al. (1998), and translated into Japanese and examined with a pilot study (Wang et al., 2016).

Nutritional knowledge of the participants regarding F\&V intake was measured with 5 items. Attitudes toward F\&V intake were assessed with a five-point Likert scale. Responsibility for food shopping and preparation was evaluated by 3 items and assessed with a three-point Likert scale. Social support was measured with 3 items.

Self-efficacy was measured with 10 items and assessed by a three-point Likert scales. Perceived barriers, including economic/distribution factors, family- and self-preference, availability when eat away from home, personal judgement and comprehension, personal habits, were measured with 18 items and each item was scored on a five-point Likert scale. Further details are described elsewhere (Wang et al., 2016).

\subsubsection{Stage of Change}

Stage of change behaviors related to increasing F\&V intake was measured for 5 eating behaviors by asking questions including "Eating 350g or more vegetables and 200g or more fruits a day most day"; "Having 100\% juice or fruit in the morning most days"; "Eating a green salad or another vegetable for lunch most days"; "Eating 
2 or more servings of vegetable for dinner most days"; "Eating more fruits and vegetables" with a four-choice response format. Based on the transtheoretical model (TTM) of behavior change (Prochaska \& DiClemente, 1983), the answers were converted to the following 4 stages: precontemplation stage (not thinking about doing it), contemplation stage (thinking about starting to do it in the next 6 months), preparation stage (definitely planning to start doing it in the next months), and action/maintenance stage (already doing it).

\subsection{Data Analysis}

We compared the proportions of subjects among the stages of change for the habits of $\mathrm{F} \& \mathrm{~V}$ intakes using Chi-square test. A trend analysis (based on linear-contrast one-way analysis of variance) was also performed to examine the relation of psycho-social factor scores, $F \& V$ intake with the stages of change. All statistical analyses were performed using IBM-SPSS for Windows (SPSS Inc., Chicago, IL, USA).

\section{Results}

Table 1 illustrates the participants' profiles. A total of 1012 men (43.8\%) and 1296 women (56.2\%) who completed the questionnaires were analyzed in the study. More than half of the participants were aged less than 30 years old, and $76.1 \%$ were college educated or higher. Half of the participants (54.2\%) reported currently working and $33.2 \%$ worked full-time (Wang et al., 2016).

Table 1. Participants' characteristics

\begin{tabular}{lll}
\hline & & $\mathrm{n}(\%)$ \\
\hline \multirow{2}{*}{ Gender } & Men & $1012(43.8)$ \\
& Women & $1296(56.2)$ \\
\hline \multirow{2}{*}{ Age } & $<30$ & $1335(57.8)$ \\
& $30-59$ & $776(33.6)$ \\
& $\geqq 60$ & $190(8.2)$ \\
School education & Non-response & $7(0.3)$ \\
& $<$ College/University & $531(23.0)$ \\
& $\geqq$ College/University & $1757(76.1)$ \\
\hline
\end{tabular}

Distribution in stage of change for increasing F\&V intake across gender was shown in Table 2. For response to the question "Eating $350 \mathrm{~g}$ or more vegetables and $200 \mathrm{~g}$ or more fruits a day most day", there was a significant difference in proportion of participants among 4 stages of change $(p<0.001)$. The largest proportion of the participants $(56.0 \%)$ answered "not thinking about doing it" (in the precontemplation stage) and $29.8 \%$ answered "thinking about starting to do it in the next 6 months" (in the contemplation stage), and men were more likely to be in precontemplation (67.7\%) and less likely to be in action/maintenance stage $(7.9 \%)$ than women $(46.9,12.1 \%$, respectively) ( $p<0.001)$. The least men $(3.7 \%)$ and women $(4.3 \%)$ were in the preparation stage.

Regarding the question "Having $100 \%$ juice or fruit in the morning most days", there was a significant difference in proportion of participants among 4 stages of change $(p<0.001)$ (Table 2$)$. About $46.8 \%$ of the participants were in the precontemplation and $25.9 \%$ in the contemplation stages. More than half of men were in precontemplation stage (55.3\%) and the proportions of men were smaller in the contemplation, preparation, and action/maintenance stages compared that of women, respectively $(p<0.001)$.

Regarding the question "Eating a green salad or another vegetable for lunch most days", there was a significant difference in proportion of participants among 4 stages of change $(p<0.001)$. Nearly half of the men $(49.9 \%)$ and one-third of the women $(30.8 \%)$ were in the precontemplation stage, and relatively small proportions of men and women were in preparation stage $(5.4 \%, 5.0 \%$, respectively) $(p<0.001)$ (Table 2$)$.

To the question "Eating 2 or more servings of vegetable for dinner most days", there was a significant difference in proportion of participants among 4 stages of change $(p<0.001)$. The proportion of men $(48.3 \%)$ in the precontemplation stage was two times higher than that of woman $(24.3 \%)$. The least men $(5.7 \%)$ and women $(5.8 \%)$ were in the preparation stage $(p<0.001)$ (Table 2).

To the question "Eating more fruits and vegetables", there was a significant difference in proportion of participants 
among 4 stages of change $(p<0.001)$. Both men $(36.1 \%)$ and women $(45.0 \%)$ were more likely to be in the contemplation stage; and higher proportion of women $(26.1 \%)$ was in the action/maintenance stages compared with that of men $(18.2 \%)(p<0.001)$ (Table 2$)$.

Table 2. Distribution in stage of change for fruit and vegetable intake across gender

\begin{tabular}{|c|c|c|c|c|c|}
\hline & \multicolumn{4}{|c|}{ Stage of Change } & \multirow{3}{*}{$\begin{array}{l}\text { Difference } \\
\text { among stage } \\
\text { (Chi-square } \\
\text { test) }\end{array}$} \\
\hline & Precontemplation & Contemplation & Preparation & Action/Maintenance & \\
\hline \multicolumn{5}{|c|}{ 1. Eating $350 \mathrm{~g}$ or more vegetables and $200 \mathrm{~g}$ or more fruits a day most day ${ }^{\#, * * *}$} & \\
\hline Total $(\mathrm{n}=2292)$ & $1283(56.0)$ & $682(29.8)$ & $92(4.0)$ & $235(10.3)$ & \\
\hline $\operatorname{Men}(\mathrm{n}=1005)$ & $680(67.7)$ & $209(20.8)$ & $37(3.7)$ & $79(7.9)$ & $p<0.001$ \\
\hline Women $(n=1287)$ & 603 (46.9) & $473(36.8)$ & $55(4.3)$ & $156(12.1)$ & \\
\hline \multicolumn{6}{|c|}{ 2. Having $100 \%$ juice or fruit in the morning most days ${ }^{* * *}$} \\
\hline Total $(n=2291)$ & $1073(46.8)$ & $594(25.9)$ & $132(5.8)$ & $492(21.5)$ & \\
\hline Men $(n=1006)$ & $556(55.3)$ & $224(22.3)$ & $52(5.2)$ & $174(17.3)$ & $p<0.001$ \\
\hline Women $(n=1285)$ & $517(40.2)$ & $370(28.8)$ & $80(6.2)$ & $318(24.7)$ & \\
\hline \multicolumn{6}{|c|}{ 3. $\quad$ Eating a green salad or another vegetable for lunch most days ${ }^{* * *}$} \\
\hline Total $(\mathrm{n}=2290)$ & 897 (39.2) & $652(28.5)$ & $118(5.21)$ & $623(27.2)$ & \\
\hline Men $(n=1006)$ & $502(49.9)$ & $228(22.7)$ & $54(5.4)$ & $222(22.1)$ & $p<0.001$ \\
\hline Women $(\mathrm{n}=1284)$ & $395(30.8)$ & $424(33.0)$ & $64(5.0)$ & $401(31.2)$ & \\
\hline \multicolumn{6}{|c|}{ 4. $\quad$ Eating 2 or more servings of vegetable for dinner most days ${ }^{* * *}$} \\
\hline Total $(n=2298)$ & 801 (34.9) & $612(26.6)$ & $132(5.7)$ & $753(32.8)$ & \\
\hline Men $(n=1008)$ & $487(48.3)$ & $216(21.4)$ & $57(5.7)$ & $248(24.6)$ & $p<0.001$ \\
\hline Women $(n=1290)$ & $314(24.3)$ & $396(30.7)$ & $75(5.8)$ & $505(39.1)$ & \\
\hline \multicolumn{6}{|c|}{ 5. $\quad$ Eating more fruits and vegetables ${ }^{* * *}$} \\
\hline Total $(n=2291)$ & $545(23.8)$ & $941(41.1)$ & $287(12.5)$ & $518(22.6)$ & \\
\hline $\operatorname{Men}(n=1006)$ & $353(35.1)$ & $363(36.1)$ & $107(10.6)$ & $183(18.2)$ & $p<0.001$ \\
\hline Women $(\mathrm{n}=1285)$ & $192(14.9)$ & $578(45.0)$ & $180(14.0)$ & $335(26.1)$ & \\
\hline
\end{tabular}

Note. \# Recommendation level of daily vegetable and fruit intake in Japan.

*** $p<0.001$ (Men vs. women by Chi-square test). Values in the parenthesis denote percentage.

The highest proportions of the subjects answered not thinking about consuming recommended amount of fruit and vegetable (in the precontemplation stage) and the subjects in this stage consumed the least amount of fruit (Figure 1A) and vegetable (Figure 1B) daily. We also found there were linear trends toward higher fruit $(p=0.121)$ and vegetable $(p<0.05)$ intakes from precontemplation to action/maintenance stage (Figure 1).

Subjects in the precontemplation stage showed lower scores of attitude and self-efficacy than in the stages of contemplation, preparation, and action/maintenance stage (Table 3$)$. We also observed the scores of attitude ( $p=$ $0.06)$, self-efficacy $(p=0.005)$ increased and the scores of responsibility decreased $(p=0.003)$ as the stage went up from the precontemplation to action/maintenance stages (Table 3). The average score of perceived barriers to increasing fruit and vegetable intakes tended to decrease as the stage went up although it was not statistically significant.

In the previous work, we found a 7-factor structure ( 2 self-efficacy factors and 5 barrier factors corresponding to loading values $>0.45$ ) was a best-fitting model for deter-mining the major factors of self-efficacy and barriers that might influence F\&V intake of the subjects (Wang et al., 2016). Table 4 demonstrates that as the stage went up from the precontemplation to action/maintenance stages, the subjects perceived more "willingness to consuming fruit and vegetable anytime" and "ability to designing meal", and had less barriers related to 
"economic/distribution factors", "personal habits".

A.

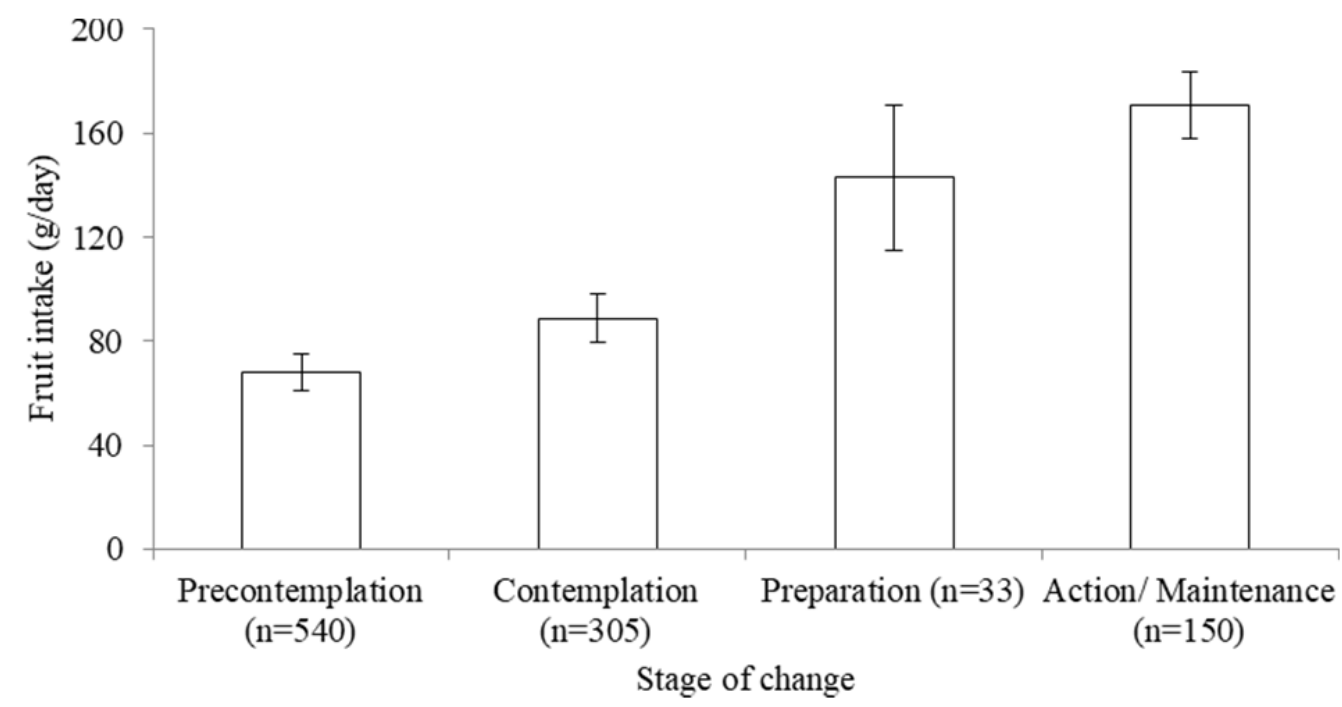

B.

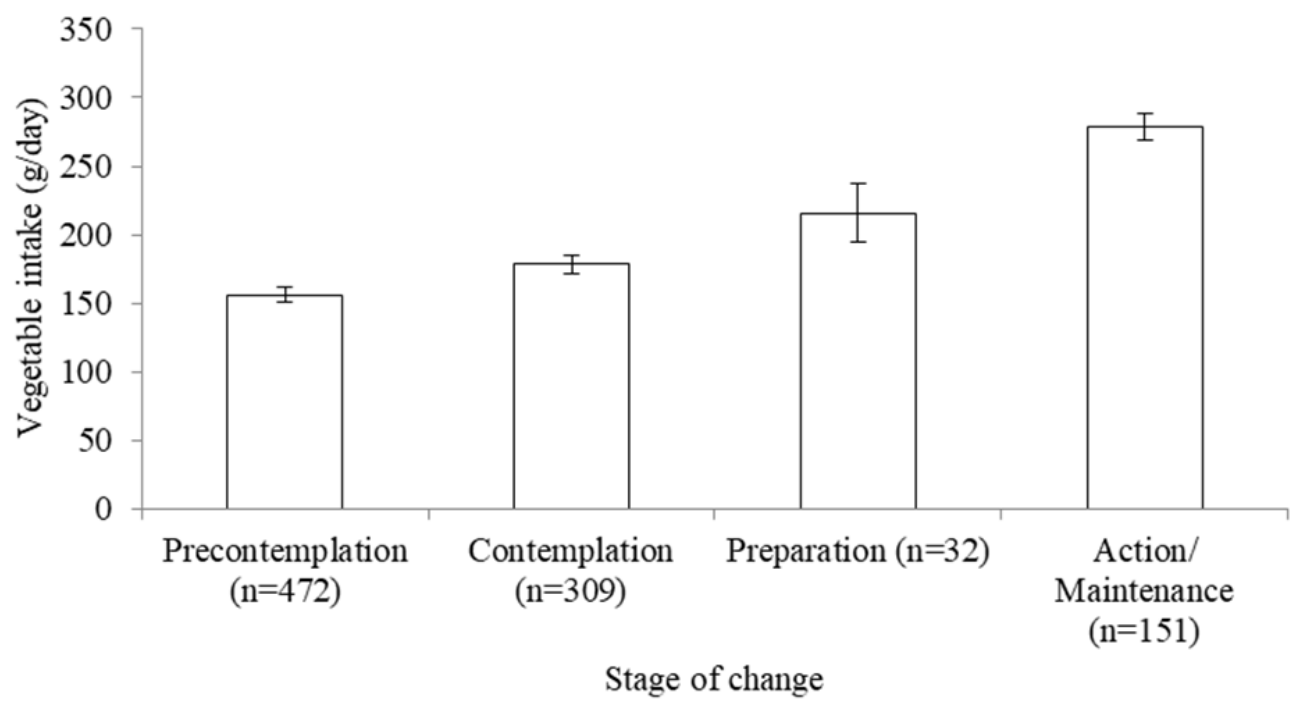

Figure 1. Self-reported daily fruit (A) and vegetable (B) intakes across the stages of change. Subjects in the precontemplation stage consumed the least amount of fruit (A) and vegetable (B) daily. After adjustment for gender, there were linear trends toward higher fruit $\left(p_{\text {Trend }}=0.121\right)$ and vegetable $\left(p_{\text {Trend }}<0.05\right)$ intakes from precontemplation to action/maintenance stage 
Table 3. Mean scores of psycho-social deterninants for fruit and vegetable intakes across the stages of change

\begin{tabular}{llllll}
\hline & \multicolumn{5}{c}{ Stage of Change } \\
\cline { 2 - 5 } & $\begin{array}{l}\text { Precontemplation } \\
(\mathrm{n}=1196)\end{array}$ & $\begin{array}{l}\text { Contemplation } \\
(\mathrm{n}=640)\end{array}$ & $\begin{array}{l}\text { Preparation } \\
(\mathrm{n}=83)\end{array}$ & $\begin{array}{l}\text { Action/Maintenance } \\
(\mathrm{n}=211)\end{array}$ & $\begin{array}{c}p_{\text {Trend }} \\
\text { Knowledge }\end{array}$ \\
Attitude & $3.0 \pm 1.0$ & $3.2 \pm 0.9$ & $3.0 \pm 0.9$ & $3.3 \pm 0.9$ & 0.089 \\
Responsibility & $6.1 \pm 2.3$ & $20.3 \pm 3.7$ & $20.9 \pm 3.4$ & $21.5 \pm 3.3$ & 0.060 \\
Social support & $1.1 \pm 1.2$ & $5.6 \pm 2.2$ & $6.1 \pm 2.2$ & $5.1 \pm 2.3$ & 0.003 \\
Self efficacy & $17.4 \pm 4.6$ & $1.4 \pm 1.2$ & $1.5 \pm 1.3$ & $1.3 \pm 1.3$ & 0.661 \\
Perceived barriers & $45.6 \pm 11.4$ & $19.1 \pm 4.0$ & $21.5 \pm 4.5$ & $22.6 \pm 4.2$ & 0.005 \\
\hline
\end{tabular}

Note. Values are mean \pm standard deviation.

\#: Trend analysis adjusted for gender.

Table 4. Tendency of self-efficacy and perceived barriers across the stages

\begin{tabular}{|c|c|c|c|c|c|}
\hline & \multicolumn{4}{|c|}{ Stage of change for increasing fruit and vegetable intakes } & \multirow[b]{2}{*}{$p_{\text {Trend }}{ }^{*}$} \\
\hline & $\begin{array}{l}\mathrm{PC} \\
(\mathrm{n}=1283)\end{array}$ & $\begin{array}{l}\text { C } \\
(n=682)\end{array}$ & $\begin{array}{l}\text { PR } \\
(n=92)\end{array}$ & $\begin{array}{l}\mathrm{A} / \mathrm{M} \\
(\mathrm{n}=235)\end{array}$ & \\
\hline \multicolumn{6}{|l|}{ Self-efficacy } \\
\hline Willingness to consuming V\&F anytime & $1.8 \pm 0.5$ & $1.9 \pm 0.4$ & $2.1 \pm 0.5$ & $2.3 \pm 0.4$ & $<0.001$ \\
\hline Ability to designing meal & $1.6 \pm 0.7$ & $1.8 \pm 0.6$ & $2.1 \pm 0.7$ & $2.1 \pm 0.7$ & 0.008 \\
\hline \multicolumn{6}{|l|}{ Perceived barrier } \\
\hline Economic/distribution factors & $3.5 \pm 1.2$ & $3.4 \pm 1.1$ & $3.1 \pm 1.1$ & $2.7 \pm 1.2$ & 0.021 \\
\hline Family and self preference & $1.6 \pm 0.8$ & $1.5 \pm 0.7$ & $1.5 \pm 0.8$ & $1.4 \pm 0.6$ & 0.106 \\
\hline Availability when eat away from home & $2.9 \pm 1.3$ & $3.0 \pm 1.3$ & $2.7 \pm 1.1$ & $2.5 \pm 1.4$ & 0.454 \\
\hline Personal judgement and comprehension & $2.5 \pm 1.0$ & $2.2 \pm 0.9$ & $2.1 \pm 0.9$ & $2.4 \pm 1.0$ & 0.63 \\
\hline Personal habits & $2.7 \pm 1.0$ & $2.5 \pm 1.0$ & $2.4 \pm 1.0$ & $2.2 \pm 1.1$ & 0.026 \\
\hline
\end{tabular}

Note. PC: Precontemplation, C: Contemplation, PR: Preparation, A/M: Action/Maintenance. V\&F: Vegetable and fruit.

$\sharp$ : Trend analysis adjusted for gender.

\section{Discussion}

The TTM of behavior change is a useful framework for research on understanding multiple behaviors in the general population (Prochaska \& DiClemente, 1983; Marshall \& Biddle, 2001). The results on the stage of change showed that more than half of the subjects were in the precontemplation stages of readiness to change for increasing F\&V intake, among them the daily F\&V intakes were much less than the recommended amount. Such a big proportion in the precontemplation can partially be ascribed to unawareness of the current recommended levels of F\&V intake and its health implication as approximately $75 \%$ and $87 \%$ were unaware of the recommendations for daily F\&V intakes, respectively, particularly in men (Wang et al., 2016). The study by Stables et al. (Stables et al., 2002) showed a significant improvement in population's F\&V intake when the strategies focused on enhancing public awareness of guideline and health implication for F\&V. Lower scores of knowledge and attitude to F\&V intake in the precontemplation stage imply that increasing the public awareness of the current recommendations and health benefits of F\&V might promote the stage transition from the precontemplation to the higher stages for $\mathrm{F} \& \mathrm{~V}$ intake.

We also found that people in the precontemplation stage were those who had lower scores of self-efficacy. Many studies have indicated that self-efficacy strongly predict health behavior change and maintenance (Lawrance \& Rubinson, 1986; Strecher, DeVellis, Becker, \& Rosenstock, 1986; Velicer, Diclemente, Rossi, \& Prochaska, 1990). 
According to social-cognitive theory (Bandura, 1986; Bandura, 1997), people with low self-efficacy always think that they cannot perform well and avoid of challenging new things, therefore increase of opportunities for shopping, designing, and preparing meals at household level may make them feel competent to purchase/prepare/plan meal with F\&V.

In addition, people in the precontemplation and contemplation stages were those who had higher scores of perceived barriers to $\mathrm{F} \& \mathrm{~V}$ intake. The most subjects also perceived higher barriers to $\mathrm{F} \& \mathrm{~V}$ intake as those of "economic/distribution factors" and "availability when eat away from home", implying a necessity of approaching to the food service industry and workplace environment to create or popularize high $\mathrm{F} \& \mathrm{~V}$ ingredients menu at the dining room of the workplace, schools, and as well to increase availability of such as low price salad bar and takeout salad box in the market.

Consistent with previous research (Ozawa et al., 2013), our study observed there was a positive movement relating F\&V intake while the stage of behavior going up (from precontemplation to action/maintenance); we also found from the precontemplation to preparation stages the social support increased as the stage went up. Social support is considered as a potential moderator of the associations between motivation and F\&V intake (McSpadden, 2016). A multicenter cross-sectional study in Japan (Kobayashi, Asakura, Suga, \& Sasaki, 2015) also demonstrated perceived family support positively associated with $F \& V$ intake. Thus, promoting social support from family members and friends might be one of the effective strategies of forward stage transition for $\mathrm{F} \& \mathrm{~V}$ intake.

We found the subjects in the early stage of behavior change (precontemplation stage) showed a negative attitude towards F\&V consumption and low knowledge score, and the scores of attitude increased as the stage went up from the precontemplation to action/maintenance stages. It is noting only $11.8 \%$ of the participants thought that 'Having a green salad or another vegetable for lunch is very important to me, and $10.9 \%$ thought "Having two or more dishes of vegetables for dinner is very important to me", implying the importance of incorporating the participants' awareness of their low $\mathrm{F} \& \mathrm{~V}$ consumption into health benefit.

To our knowledge, this study is the first published work addressing the stage of readiness to change for F\&V consumption and its relation with psycho-social determinants of F\&V intake in varying regions of Japan. Although the current findings will be useful for the development of effective nutritional intervention programs in Japan, there are also limitations. First, it was a cross-sectional study and it limited to a number of participants in 4 regions of Japan by a conventional recruitment process, the findings may be affected by selection bias. Future study with sample groups from the other regions of Japan is needed. Second, self-reported measure on F\&V intake might introduce some reporting bias although the average daily $F \& V$ intakes reported by our participants were consistent with the latest results of the National Health and Nutrition Survey in Japan (National Institute of Health and Nutrition, 2011; National Institute of Health and Nutrition, 2015). Third, since data on household income of the participants were not available, we could not exclude the possibility of a potential confounding by socio-economic status.

In conclusion, our findings provide the evidence that majority of the subjects was in the precontemplation stage, and among them the scores of knowledge, attitude, and self-efficacy were relatively low in comparition with those in the other stages. The identified differences in stage of change and psycho-social characteristics of $\mathrm{F} \& \mathrm{~V}$ intake-related behaviors in this study may serve as a reference for tailoring future intervention programs, in which gender-specific approach should be considered.

\section{Acknowledgments}

We would like to thank Dr. Stephen Havas for providing a sample of the food survey questionnaire (Havas et al., 1998). We also acknowledge the important contributions of Prof. Yukie Yamashita (The University of Shimane Junior College), Prof. Junko Kawanaka (The University of Shimane), Ms. Mizue Nagata (Registered Nurse), and all participants in this study. Dr. Michiko Kogashiwa and Dr. Naoko Mori contributed equally to this work.

\section{Competing Interests Statement}

The authors declare that there are no competing or potential conflicts of interest.

\section{References}

Bandura, A. (1986). Social foundations of thought and action: A social cognitive theory. Prentice-Hall series. In: Social learning theory (Chapter xiii, P. 617). Prentice-Hall, Inc. Englewood Cliffs, New Jersey.

Bandura, A. (1997). Self-efficacy: The exercise of control. W. H. Freeman: New York.

Bazzano, L. A., Serdula, M. K., \& Liu, S. (2003). Dietary intake of fruits and vegetables and risk of cardiovascular disease. Current Atherosclerosis Reports, 5, 492-499. PMid:14525683. 
https://doi.org/10.1007/s11883-003-0040-z

Block, G., Patterson, B., \& Subar, A. (1992). Fruit, vegetables, and cancer prevention: a review of the epidemiological evidence. Nutrition and Cancer, 18, 1-29. PMid:1408943. https://doi.org/10.1080/01635589209514201

Boeing, H., Bechthold, A., Bub, A., Ellinger, S., Haller, D., Kroke, A., .. \& Watzl, B. (2012). Critical review: vegetables and fruit in the preven- tion of chronic diseases. European Journal of Nutrition, 6, 637-663. PMid:22684631; PMCid:PMC3419346. https://doi: 10.1007/s00394-012-0380-y

Byberg, L., Bellavia, A., Orsini, N., Wolk, A., \& Michaëlsson, K. (2015). Fruit and vegetable intake and risk of hip fracture: A cohort study of Swedish men and women. Journal of Bone and Mineral Research, 30, $976-984$. PMid:25294687. https://doi.org/10.1002/jbmr.2384

Hartley, L., Igbinedion, E., Holmes, J., Flowers, N., Thorogood, M., Clarke, A., ... \& Rees, K. (2013). In: Cochrane review: Increased consumption of fruit and vegetables for the primary prevention of cardiovascular diseases. The Cochrane Collaboration, The Cochrane Library, John Wiley \& Sons, Ltd., USA, 2013, 6. https://doi.org/10.1002/14651858

Havas, S., Treiman, K., Langenberg, P., Ballesteros, M., Anliker, J., Damron, D., \& Feldman, R. (1998). Factors associated with fruit and vegetable consumption among women participating in WIC. Journal of the American Dietetic Association, 98, 1141-1148. https://doi.org/10.1016/S0002-8223(98)00264-8

Joshipura, K. J., Ascherio, A., Manson, J. E., Stampfer, M. J., Rimm, E. B., Speizer, F. E., ... \& Willett, W. C. (1999). Vegetable and fruit intake in relation to ischemic stroke. The Journal of the American Medical Association, 282, 1233-1239. https://doi.org/10.1001/jama.282.13.1233

Kato, S. (2011). Relationships among Motivations of Food Choice, Food Intake, Health Locus of Control, and Self-efficacy in University Students. Bulletin of Kyoto Notre Dame University, 41, 1-17. [In Japanese]

Kato, S., Watanabe, S., Haga, H., Imada, S., \& Osada, H. (2014). Relationship with food choice motives, the vegetable choice, self-rated health and personal attributes of the elderly females. Journal for the Integrated Study of Dietary Habits, 25, 191-202. [In Japanese]https://doi.org/10.2740/jisdh.25.191

Kobayashi, S., Asakura, K., Suga, H., \& Sasaki, S. (2015). Cohabitational effect of grandparents on dietary intake among young Japanese women and their mothers living together. A multicenter cross-sectional study. Appetite, 91, 287-297. https://doi: 10.1016/j.appet.2015.04.059

Lawrance, L., \& Rubinson, L. (1986). Self-efficacy as a predictor of smoking behavior in young adolescents. Addictive Behaviors, 11, 367-382. https://doi.org/10.1016/0306-4603(86)90015-8

Marshall, S. J., \& Biddle, S. J. H. (2001). The transtheoretical model of behavior change: a meta-analysis of applications to physical activity and exercise. Annals of Behavioral Medicine, 23, 229-246. PMid:11761340. https://doi.org/10.1207/S15324796ABM2304_2

McSpadden, K. E., Patrick, H., Oh, A. Y., Yaroch, A. L., Dwyer, L. A., \& Nebeling, L. C. (2016). The association between motivation and fruit and vegetable intake: The moderating role of social support. Appetite, 96, 87-94. PMid:26321416 PMCid:PMC4684708. https://doi: 10.1016/j.appet.2015.08.031

Ministry of Agriculture, Forestry and Fisheries, Japan. Guidelines for balanced diet. June (2005).

Ministry of Health, Labour and Welfare, Japan. Health Japan 21 (The National Health Promotion Movement in 21 st Century), (2000).

National Institute of Health and Nutrition. (2011). Outline for the Results of the National Health and Nutrition Survey Japan. [in Japanese]

National Institute of Health and Nutrition. (2015). Outline for the Results of the National Health and Nutrition Survey Japan. [in Japanese]

Okamoto, M., Nakao, N., \& Muto, K. (2015). Study on Factors Influencing the Intake of Vegetable at Various Steps of Behavior Modification of Women's College Students. Nagasaki International University Journal, 15, 119-134. [in Japanese]

Ozawa, K., Takemi, Y., Eto, K., Tanaka, H., Fujii, H., Ishikawa, M., \& Yokoyama, T. (2013). Stage of vegetable intake and self-reported number of vegetable dishes consumed: Are they valid measures of vegetable intake among middle-aged adults? The Japanese Journal of Nutrition and Dietetics, 71, 97-111. https://doi.org/10.5264/eiyogakuzashi.71.97 
Prochaska, J. O., \& DiClemente, C. C. (1983). Stages and processes of self-change of smoking: toward an integrative model of change. Journal of Consulting and Clinical Psychology, 51, 390-395. https://doi.org/10.1037/0022-006X.51.3.390

Shaikh, A. R., Yaroch, A. L., Nebeling, L., Yeh, M. C., \& Resnicow, K. (2008). Psychosocial predictors of fruit and vegetable consumption in adults: a review of the literature. American Journal of Preventive Medicine, 34, 535-543. PMid:18471592. https://doi.org/10.1016/j.amepre.2007.12.028

Stables, G. J., Subar, A. F., Patterson, B. H., Dodd, K., Heimendinger, J., Van Duyn, M. A., \& Nebeling, L. (2002). Changes in vegetable and fruit consumption and awareness among US adults: results of the 1991 and 19975 A Day for Better Health Program surveys. Journal of the American Dietetic Association, 102, 809-817. https://doi.org/10.1016/S0002-8223(02)90181-1

Strecher, V. J., DeVellis, B. M., Becker, M. H., \& Rosenstock, I. M. (1986). The role of self-efficacy in achieving health behavior change. Health Education Quarterly, 13, 73-92. PMid:3957687. https://doi.org/10.1177/109019818601300108

Van't Veer, P., Jansen, M. C., Klerk, M., \& Kok, F. J. (2000). Fruits and vegetables in the prevention of cancer and cardiovascular disease. Public Health Nutrition, 3, 103-107. PMid:10786730. https://doi.org/10.1017/S1368980000000136

Velicer, W. F., Diclemente, C. C., Rossi, J. S., \& Prochaska, J. O. (1990). Relapse situations and self-efficacy: an integrative model. Addictive Behaviors, 15, 271-283. https://doi.org/10.1016/0306-4603(90)90070-E

Wakai, K., Sugawara, Y., Tsuji, I., Tamakoshi, A., Shimazu, T., Matsu, K., ... \& Research Group for the Development and Evaluation of cancer Prevention Strategies in Japan. (2015). Risk of lung cancer and consumption of vegetables and fruit in Japanese: A pooled analysis of cohort studies in Japan. Cancer Science, 106, 1057-1065. PMid:26033436 PMCid:PMC4556396. https://doi.org/10.1111/cas.12707

Wang, D. H., Kogashiwa, M., Mori, N., Yamashita, S., Fujii, W., Ueda, N., ... \& Masuoka, N. (2016). Psychosocial determinants of fruit and vegetable consumption in a Japanese population. International Journal of Environmental Research and Public Health, 13(8). pii: E786. PMid:27527198 PMCid:PMC4997472. https://doi.org/10.3390/ijerph13080786

Watters, J. L., Satia, J. A., \& Galanko, J. A. (2007). Associations of psychosocial factors with fruit and vegetable intake among African-Americans. Public Health Nutr ition, 10, 701-711. PMid:17381950. https://doi.org/10.1017/S1368980007662284

\section{Copyrights}

Copyright for this article is retained by the author(s), with first publication rights granted to the journal.

This is an open-access article distributed under the terms and conditions of the Creative Commons Attribution license (http://creativecommons.org/licenses/by/4.0/). 